\title{
Analysis of the Development Direction of Chinese Apparel Brands under the Guidance of the SPA Mode
}

\author{
H.J. DU, Y. LIU* \\ Jilin University, Changchun, Jilin, China
}

*Corresponding Author

\begin{abstract}
Today, Chinese garment industry has gradually bidden farewell to the "brand development" era and turned to the "full competition of domestic and foreign brands" stage. Under this double-tight inside and outside condition, accelerating the transformation, upgrading of China's garment industry, enhancing independent innovation capability and looking for their management mode have been pressing. SPA mode as a fast fashion brand management mode is also concerned. In this paper, I will put forward strategic suggestions on the development of Chinese apparel brands after introducing the SPA mode theory and analyzing the difference between the SPA mode and the traditional mode.
\end{abstract}

KEYWORD: SPA mode; Traditional mode; Development strategy

\section{THE THEORY OF SPA MODE}

\subsection{The definition of SPA}

SPA is the abbreviation of Specialty Retailer of Private Label Apparel.[4] The concept of SPA was put forward by Donald Fischer, the chairman of GAP, in 1986. UNIQLO and MUJI also blew up a SPA hurricane in Japan's fashion industry.

\subsection{The characteristics of SPA mode}

SPA mode has the following features: (1) Direct control of consumer information; (2) Simplify the supply chain, to substantially reduce logistics costs and time; (3) Minimize the risk of demand forecasting to supply rapidly; (4) Unique, innovative product planning; (5) Achieve quick return of funds[1].

\subsection{The core of the SPA mode}

From GAP and UNIQLO to ZARA, the changes of these three generations of the SPA mode, also let it has an essential tremendous change.

\subsubsection{The essence of SPA is speed and profit}

Due to the multicultural market now, the company which is the first one produces the best-selling will gets the biggest profits and smallest inventory. The requirements of speed and profit are increasing the processing speed from manufactory to store, and avoiding unnecessary intermediate links.

\subsubsection{Merchandising $(M D)$ decides the design direction of the goods}

MD decides the design direction of the goods is the core value of the SPA mode. MD is a work that determines the number of categories, styles and so on. It is based on the integration of marketing research and the analysis of the competitive products, market and fashion. Design is a work that is full of emotions. However, design whether can joint market demands is controlled by MD.

\subsubsection{The actual sale of goods determines the display mode}

The traditional display is according to the need of promotion. But the core concentration of SPA is that the actual sale of goods determines the display mode. Display is the most intuitive feel to the brand for consumers. The performance feedback will get a very good result through continuous display [4].

\section{THE DEVELOPMENT STATUS OF SPA ENTERPRISE}

As the father of the SPA mode, GAP has expanded since the 90's. After the development, the sales area increased 5.6 times and shares raised more than 300 times, that created a myth. Then this business mode was applied by Japan's Fast Retailing, and it established its own SPA mode. It is "Affordable Wild" own-brand retail mode that is used to deal with Japan's depressed economic situation. When 
GAP was developing rapidly, the amount of sales of UNIQLO was just over 100 billion yen. However, until the end of 2013, the amount of sales of UNIQLO had exceeded 1 trillion yen (Fig. 1). ZARA and $\mathrm{H} \& \mathrm{M}$ also gave SPA mode the concept of affordable fashion and rapid response by establishing its own SPA mode. In just a few decades, ZARA put a lot luxury brands which had developed for a century left behind (Fig. 2, Fig. 3). The domestic N\&Q and HEILAN HOME have developed and grown stronger and successfully listed by importing SPA mode in recent years.

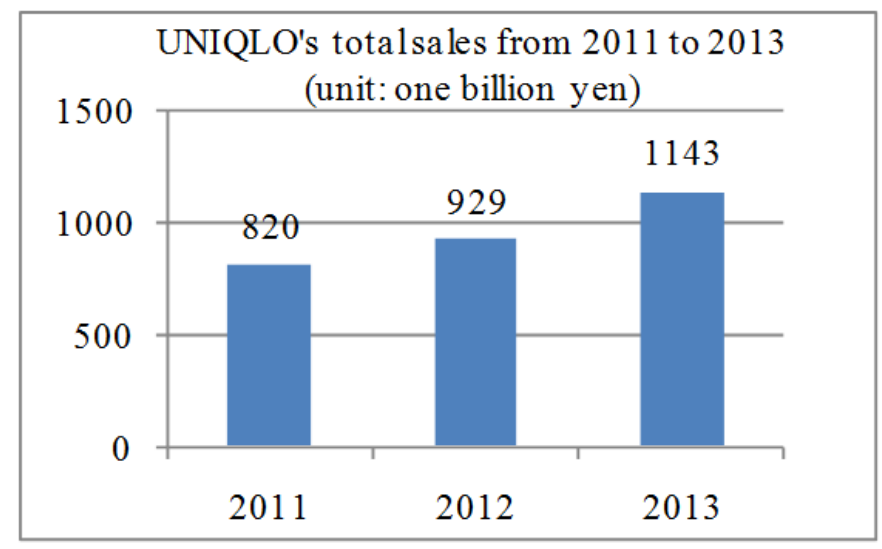

Figure 1. UNIQLO's total sales from 2011 to 2013

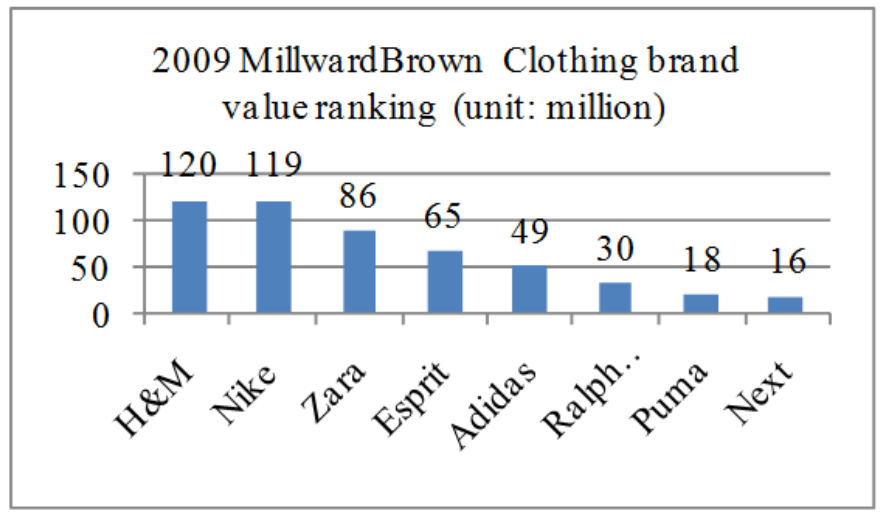

Figure 2. 2009 MillwardBrown Clothing brand value ranking

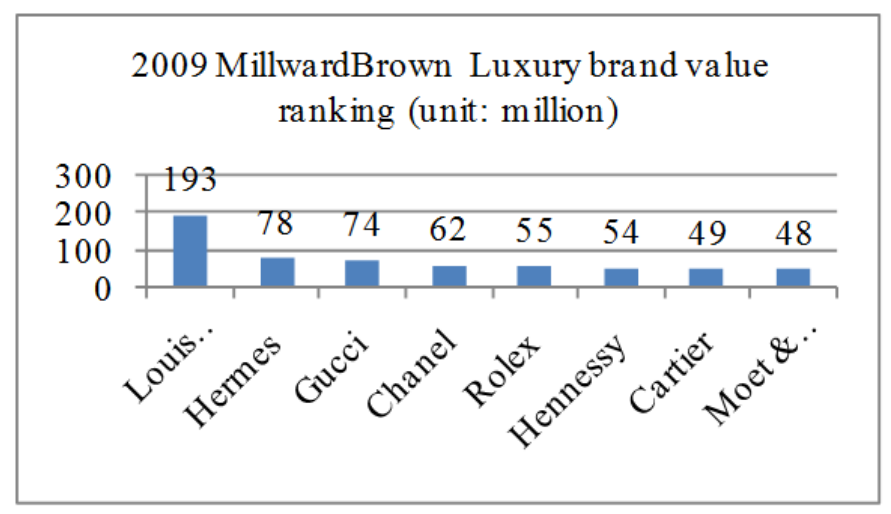

Figure 3. 2009 MillwardBrown Luxury brand value ranking

\section{COMPARISON BETWEEN SPA MODE AND TRADITIONAL MODE}

\subsection{Management mode}

Traditional management mode starts from the fashion information collection to the proposed design concept then to production delivery and final sales. This process is at least eight or nine months. However, from the point of fashion, expecting the next year's fashions in the case of one year ahead has a considerable risk. If the predictions are accurate, it will sell large, otherwise it will cause a lot of inventory. The fast fashion brand regards pursuiting quick reaction of the management mode as a benchmark because of the ever-changing fashion industries. It must quickly meet the needs of the consumers. It abandoned the traditional management mode that predicted the tendency of the popular way a year in advance and created a highly efficient mode of operation of fast, low-cost, multistyle and a small number [5].

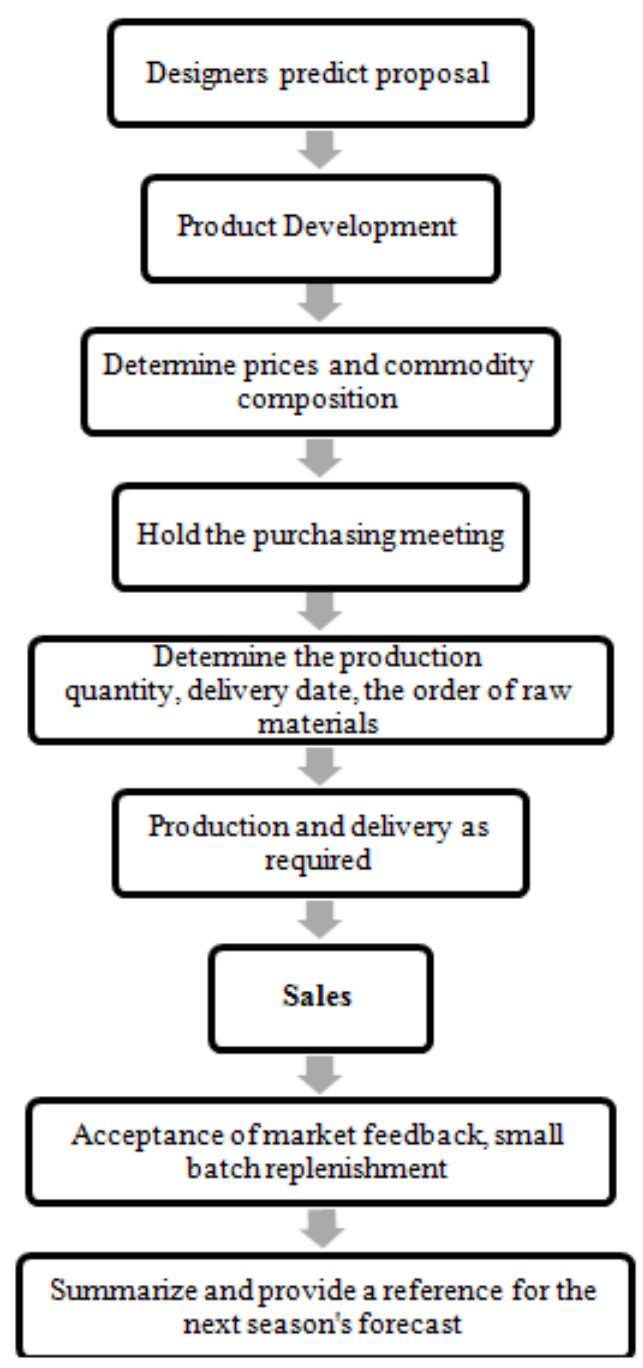

Figure 4. Traditional clothing enterprise management mode 
Consumer demand in a timely manner

Product managers and designers's captures of demand information

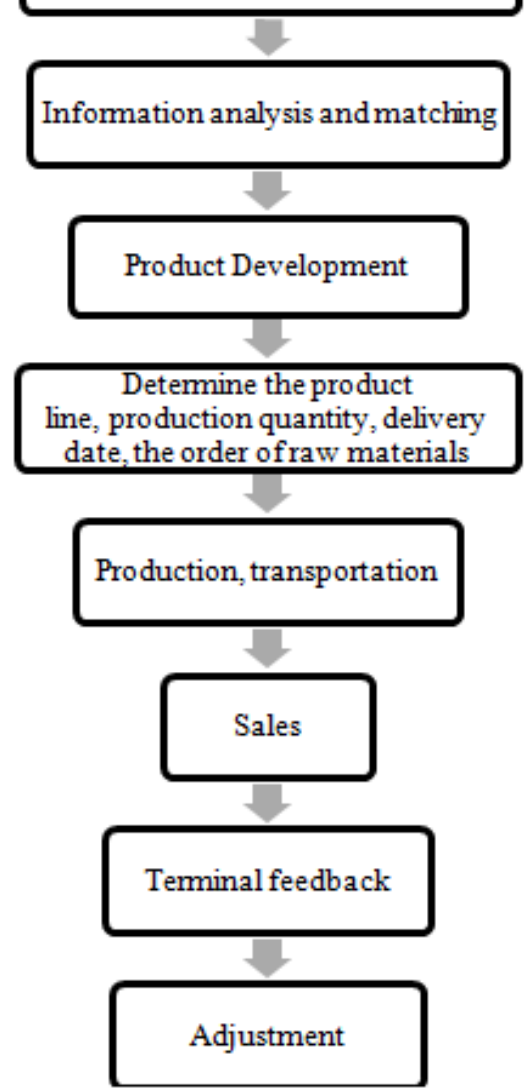

Figure 5. SPA clothing enterprise management mode

From Figure4, Figure5, the traditional management mode can be divided into: precollection, design - sales, replenishment. SPA management mode can be divided into: demand consolidation and analysis, design - sales, replenishment and commodity adjustment. (1) SPA enterprise focuses on the collection of demand information. It must understand the needs of terminal shops and combine with the trends in order to analyze and match. (2) From product design and development to sales, it can be seen clearly that SPA is much shorter than traditional enterprise management process. SPA enterprise omits the purchasing meeting; it directly bases on store sales, information feedback and the shop's area to confirm the product line. Shortening the time from design to production is conducive to the establishment of a rapid response mechanism. (3) In later stages of product sales, SPA companies will make adjustments according to the regional sales of goods, while the traditional management mode will simply replenish. SPA enterprise focuses on the needs of customers, understand customers' buying habits and dress styles and the intent of the customer to buy through the sale of the shop in order to adjust goods to make the potential demand of the customers satisfied [3].

\subsection{Merchandising Process Comparison}

One of the essentials of SPA is "The leadership of merchandising and supply," so we can see whether merchandising is effective, it will directly affect the success of the SPA. The most notable feature of modern merchandising is the function of comprehensive, in-depth, analysis, planning, implementation, control and so on. The ultimate purpose of merchandising is to infuse vigor. In the SPA process of product planning, emphasis will be placed on product design, category structure, delivery and pricing strategies to develop a suitable planning program business that meet the development goals and the needs of the target.

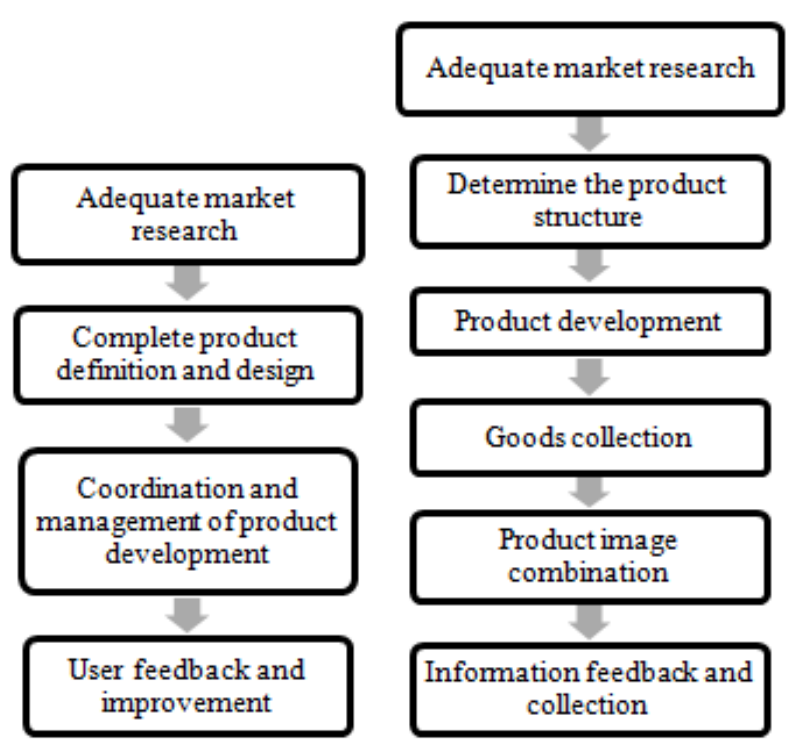

Figure 6. Traditional merchandising processes (on the left) and SPA merchandising process (on the right)

As shown in Figure 6, the traditional merchandising includes: adequate market research, complete product definition and design, coordination and management of product development and user feedback and improvement. The SPA merchandising also starts from the data. First of all, it builds the overall product structure and product structure of different levels of shops. It divides the store products proportion according to the store's characteristics, the store's effective display area size and store sales level. In product research and development, it designs and develops according to the structure of the products which according to the analysis of the trends and the in-depth research on color, fabric, profile, design, technology and even the price, combined with last year's sales. Because fashion is constantly changing, in the late stage of product development, SPA companies will also do some goods collection to avoid single impact sales. 
It can be said that the traditional merchandising and SPA mode are both starting from the data, and then carrying out product development, product implementation and information feedback process. However, SPA merchandising can make more detailed planning work.

\section{THE SUGGESTIONS OFCHINA'S SPA ENTERPRISES' STRATEGIC}

SPA is a powerful tool towards the weak. As for the China's market, although many companies have begun to implement the SPA mode in business operations applications, however, the development is still not mature enough; it cannot achieve the level of development different from the international markets. Through the comparison between traditional mode and SPA mode, concluded the followings, for Chinese clothing brand to enhance brand value as the reference.

\subsection{Improve the brand with suppliers, manufacturers of cooperation strategy}

At present, many Chinese brands are in a fragmented state, enterprises, suppliers, and manufacturers regard their own interests as large, and not form a chain of interest. When the suppliers, manufacturers and enterprises have the same target, it can increase production speed, improve product quality and reduce the cost of goods, and the brands' competitiveness will finally upgrade.

\subsection{Strengthen the brand marketing}

Due to the limitations of Chinese brands' development course, many brands are carried out by the regional agency in charge of sales. Agents and franchisees for an independent brands, is critical way to generate interest. However, brand managers will lose the right to shop for unified management and cannot guarantee the unity of the terminal store image. If store image becomes diversiform, the product orientation will be an impact. Therefore, strengthen marketing efforts for the development of an independent brand has important influence.

\subsection{Information Sharing}

Apparel products are market - driven to meet consumer demand as the goal, therefore, market information, consumer demand for information is the core of apparel products. Information sharing mechanism requires that all terminals must send the store daily sales and customer demand information back to headquarters via the information system on time. Then companies can accord to product sales, market reaction to good advance chasing a single, a good product on the part of the regional timely allocation. So it can maximize common interests.

Information sharing system enables the company to obtain the original sales data. The company can base on these data do analysis, understand the market demand, the market judge. Combined with the analysis results, trends can be a new season of merchandise planning.

\subsection{Enhance merchandising capabilities}

SPA advocates a weekly basis trimming type merchandising mode. The first step is to decrease the time from placing an order to supply commodities cycle, build establishment of production systems to additional orders, in order to reduce inventory and losses; the second step is the timing of the collection of major shops' sales information, after analysis, to achieve a weekly basis of product planning.

MD can be said that is the core of the SPA, merchandising determines the structure of the terminal display of goods, color distribution, display effects and so on. MD determines the design direction. However, many Chinese enterprises are lack of professional planner; just make a simple product MD categories according to the reaction of the market.

\section{CONCLUSIONS}

At present, Chinese apparel brands are still in exploring the SPA mode stage, but the SPA mode is not fixed and unified. However, its core is fixed; and it is to achieve rapid response for the customer needs. Apparel brands have their own characteristics, so they must combine with the situation of companies or brands to develop their own SPA mode rather than in full accordance with ZARA, UNIQLO and other success stories.

\section{REFERENCES}

[1] Chen, W.Y. 2010. SPA Business Model of Domestic Apparel Retail. Chemical Fiber \& Textile Technology 39(1):51-54.

[2] He, F. 2012. Marketing Channel Mode of SPA Apparel Company Based on the Theory of Constrains. Shanghai: Donghua University.

[3] Hu, M.M. \& Wu, G.R. 2005. The SPA emerges and functions. Journal of Textile Research 26(06):136-138.

[4] Yang, D.J.2009. The revolution of mode. Beijing: China Textile \& Apparel Press.

[5] Zhao, Q.Y. 2010. Applied research on SPA in Chinese apparel enterprises. Beijing: Beijing Institute of Fashion Technology. 